\title{
COMUNICAÇÃO
}

\section{AVALIAÇÃO DE MÁQUINAS E EQUIPAMENTOS QUE OFERECEM RISCOS À SEGURÁNÇA DO TRABALHADOR NAS ETAPAS DE PÓS-COLHEITA DO CAFÉ}

\author{
Evaluation of machines and equipment that offer risks to the security of the \\ worker in the stages of after-harvest of the coffee
}

\author{
Cinara da Cunha Siqueira Carvalhoํㅜㄹ Flávio Meira Borém², Giovanni Francisco Rabello
}

\begin{abstract}
RESUMO
A Lei Brasileira $n^{\circ}$ 6.514, de 22 de dezembro de 1977 (BRASIL, 2004) e as leis aprovadas pela portaria $\mathrm{n}^{\circ} 3.067$, de 12 de abril de 1988 que cuida das questões de saúde e segurança do trabalhador, prometem o direito subjetivo do trabalhador urbano e rural, a redução dos riscos do trabalho mediante normas de saúde, higiene e segurança. Considerando que essas leis atualmente estão sendo aplicadas em fazendas e unidades de processamento de café, no intuito de preservar o bem-estar do trabalhador, conduziu-se este trabalho, com o objetivo de avaliar o estado de conservação de máquinas e equipamentos que podem oferecer riscos à saúde e comprometer a segurança do funcionário, e verificar sua conformidade com as normas regulamentadoras durante a fase de pós-colheita de café. Foram observados e registrados os riscos oferecidos pelas máquinas e equipamentos, existentes em trinta unidades de beneficiamento de café do município de São Sebastião do Paraíso - MG, e avaliados de forma qualitativa. Foi observado que o estado de conservação desses equipamentos é irregular, pois apresentam ruído, temperaturas extremas, poeira e oferecem riscos de choques e acidentes mecânicos que comprometem a saúde do trabalhador.
\end{abstract}

Termos para indexação: Segurança no trabalho, normas regulamentadoras, café.

\section{ABSTRACT}

The Brazilian Law $n^{\circ}$. 6.514, of December 22, 1977 and the approved laws for the entrance ${ }^{\circ} 3.067$, of April 12, 1988 that take care of the subjects of health and the worker's safety, promise the urban and rural worker's subjective rights, such as the reduction of the risks of the work by norms of health, hygiene and safety. Considering that those laws are now being applied in farms and processing coffee units aiming of preserving the worker's well-being, the present work had as objective to evaluate the state of conservation of the machines and equipments that can offer risks to the health to compromise the employee's safety and to verify their conformity with the regulating norms during the stage of coffee after-harvest. The risks offered were observed and registered by the machines and equipments, existent in thirty improvement units of coffee in the municipal district of São Sebastião do ParaísoMG, and appraised in a qualitative way. It was observed that the state of conservation of those equipments is irregular, because they present noise, extreme temperatures, dust and offer risks of shocks and mechanical accidents that compromise the worker's health.

Index terms: Safety in the work, regulating norms, coffee.

(Recebido em 20 de setembro de 2005 e aprovado em 7 de agosto de 2006)

A saúde e a segurança no trabalho é, atualmente, assunto de destaque nas propriedades rurais e nas unidades de armazenamento e beneficiamento de café, em conseqüência das exigências feitas pelas empresas exportadoras e pelo mercado consumidor que se preocupam com o bem-estar do trabalhador (BINDER et al., 2001; JANSSON \& JACOBSSON, 1988; LUPI, 1985; OLIVEIRA et al., 1995; PERES et al., 2004).

A implantação das Normas Regulamentadoras do Ministério do Trabalho e do Emprego, é o meio que os produtores estão utilizando para alcançar melhores preços do café, a partir da comercialização de um produto que deixa de ser uma commodity e que passa a possuir valores agregados na sua contextualização (GLOBAL EXCHANGE, 2004; LACERDA, 1998; MEKAY, 2005). No entanto, a certificação e a busca à conformidade com as normas regulamentadoras ainda não é uma prática comum entre os cafeicultores, seja por falta de informação ou por não perceberem os ganhos econômicos que poderão ter se adotarem tais normas, tanto no campo como durante a realização das etapas de processamento do café.

${ }^{1}$ Engenheira Agrícola, Doutoranda em Engenharia Agrícola - Departamento de Engenharia Agrícola/DEA - Unviersidade Federal de Viçosa/UFV Avenida PH Rolfs, s/n - Campus Universitário - 36570-000 - Viçosa, MG - cinarasiqueira@yahoo.com.br

Engenheiro Agrônomo, Pós-doutor em Engenharia de Processamento de Produtos Agrícolas - Departamento de Engenharia/DEG - Universidade Federal de Lavras/UFLA - Cx. P. 3037 - 37200-000 - Lavras, MG - flavioborem@ufla.br

${ }^{3}$ Engenheiro Eletricista, Doutor em Engenharia Agrícola - Departamento de Engenharia/DEG - Universidade Federal de Lavras/UFLA - Cx. P. 3037 37200-000 - Lavras, MG - giovannirabelo@yahoo.com.br 
Neste contexto, objetivou-se com este trabalho diagnosticar os riscos à saúde e à segurança do trabalhador oferecidos pelas máquinas e equipamentos utilizados em cada uma das etapas da pós-colheita do café, e a conformidade das unidades de processamento do café às normas regulamentadoras rurais.

O trabalho foi realizado no Departamento de Engenharia Agrícola da Universidade Federal de Lavras e na Cooperativa Agrícola de São Sebastião do Paraíso COOPARAÍSO.

Foram aplicados questionários a proprietários ou gerentes de trinta propriedades pertencentes a três associações rurais do município de São Sebastião do Paraíso - MG, que foram sorteadas e visitadas. Além disso, observações in loco e registros fotográficos foram realizados, e analisados em função do nível tecnológico da propriedade, da seguinte forma: as propriedades que não realizavam todos os tratos culturais na lavoura, não possuíam maquinário específico e não realizavam todas as etapas do processamento na fazenda foram classificadas em nível tecnológico baixo. As propriedades que realizavam todos os tratos culturais, processavam o café no local, tinham maquinário específico para as atividades, mas as instalações estavam em estado regular de conservação, não forneciam treinamento para os funcionários e não se preocupavam com a preservação do meio ambiente, foram classificadas em nível tecnológico médio. As propriedades que realizavam todos os tratos culturais, possuíam maquinário e instalações para a realização de todas as atividades e que se encontravam em ótimo estado de conservação, forneciam treinamento para os funcionários e tinham preocupação com a preservação do meio ambiente foram classificadas em nível tecnológico alto.

Durante a análise dos riscos oferecidos pelos equipamentos e maquinários utilizados em cada etapa do processamento, foram observados os seguintes itens: ruído, eliminação de poeira, estado de conservação das

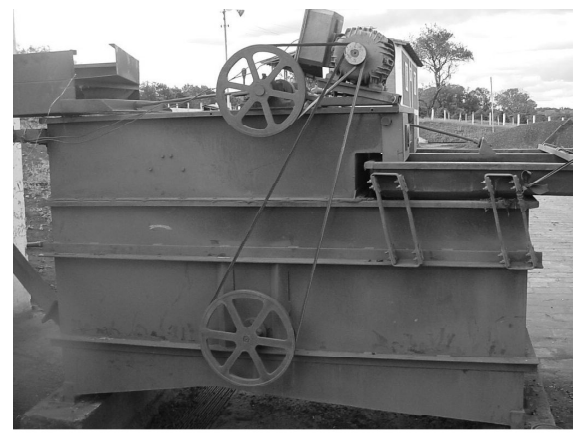

(a) máquinas e das instalações elétricas, e presença ou ausência de estruturas de proteção contra quedas ou que possam oferecer riscos mecânicos.

Os dados coletados foram analisados segundo a estatística descritiva. As variáveis qualitativas foram estratificadas em classes como excelente, bom, ruim e péssimas e apresentadas por meio de tabelas de frequiência e gráficos em porcentagem. As variáveis quantitativas foram apresentadas em forma de porcentagem.

Com relação ao nível tecnológico, das 30 propriedades visitadas, somente $47 \%$ realizam todas as atividades relacionadas aos tratos culturais, tais como: análise de solo, análise foliar, adubação, correção do pH do solo e controle de pragas e doenças. A partir da realização dos tratos culturais, maquinário e forma de realização das etapas de pós-colheita, foi possível separar as propriedades quanto ao nível tecnológico, $80 \%$ foram classificadas em nível tecnológico baixo, $10 \%$ em nível tecnológico médio e $10 \%$ em nível tecnológico alto.

O equipamento utilizado para fazer a separação do café é o lavador, que acaba por realizar duas atividades, a de lavar o produto retirando as impurezas que chegam da lavoura e separar o café de acordo com a sua densidade.

A porcentagem de propriedades visitadas que possuíam lavador mecânico foi de $17 \%$, sendo que somente $3 \%$ das propriedades estavam com todo o conjunto em excelente estado de conservação. No entanto, em todas as propriedades o funcionamento deste equipamento gerava ruído elevado e, em somente 3\% das propriedades, os funcionários estavam usando protetor auricular.

O lavador ilustrado, nas Figuras 1(a) e (b), destaca os riscos existentes aos trabalhadores devido à má conservação do maquinário. A falta de proteção e segurança em torno das polias (que estão expostas) podem ser observadas com maior detalhe na Figura 1(a). Na Figura 1(b), observa-se um improviso à base de um pedaço de borracha amarrado ao braço da estrutura que estava quebrado.

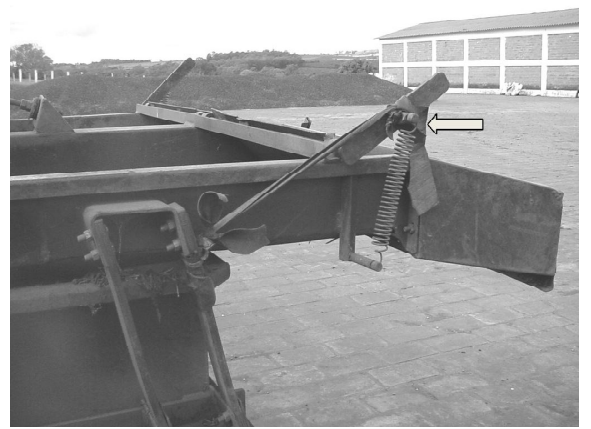

(b)

Figura 1(a) - Lavador com polias expostas, (b) detalhe do improviso para amarração da peça. 
Outro risco existente na área de separação do café é o acionamento e estado de conservação do painel de comando que é regulamentado pelo item 12.2.1 da NR 12 da Portaria $\mathrm{n}^{\circ} 3.214$ de 8 junho de 1978 . As máquinas e os equipamentos devem ter dispositivos de acionamento e parada, localizados de modo que possam ser acionados ou desligados pelo funcionário na sua posição de trabalho e por outro funcionário que não seja o responsável pelo funcionamento do equipamento (alínea a, c). Somente 17\% das propriedades possuíam painel de comando. Nestas, em $60 \%$, o painel estava em péssimo estado de conservação, oferecendo riscos de choque aos trabalhadores, que ocorrem em consequiência da fiação exposta, contato com água, partes elétricas do lavador sem proteção e painel de comando sem proteção. Os riscos observados no painel de controle estão ilustrados nas Figuras 2 e 3 . A fiação elétrica do lavador, demonstrada na Figura 2, está totalmente exposta, oferecendo riscos de choque ao trabalhador. A Figura 3 mostra que o painel de comando está ao ar livre e susceptível às intempéries do local, além de estar muito próximo da vegetação, favorecendo o risco de choques e incêndio.

Durante o processo de secagem no terreiro, ferramentas e máquinas são utilizadas para movimentar o café, entretanto a má utilização destas pode causar problemas ergonômicos ao trabalhador, lombalgia, além dos riscos existentes à exposição solar. As ferramentas mais utilizadas são: rodo, encontrado em $100 \%$ das propriedades visitadas, $70 \%$ possuíam vassouras, e o trator, encontrado em somente $23 \%$ das propriedades. Nas propriedades visitadas, foi observado que nenhum trator possuía cabine de proteção, recomendada pelo item 18.22.4 da NR 18. A falta de proteção no trator pode ser verificada através da Figura 4, além da não utilização dos equipamentos de proteção individual por parte do condutor. A Figura 5 ilustra outra atividade relacionada com a movimentação do café no terreiro, onde a bomba costal é utilizada para amontoar o café. O peso da bomba, assim como o rodo, causam dores na coluna e nos braços. Dores físicas foram relatadas por $27 \%$ dos entrevistados, em função do peso dos rodos e postura inadequada dos operadores durante as atividades com o trator.

Somente $30 \%$ das propriedades possuíam secadores. Verificou-se que: quanto maior o nível tecnológico, maior o número de secadores existentes nas propriedades, o que pode ser explicado pela maior capitalização e acesso à tecnologia por parte destes produtores. Dentre as propriedades de nível tecnológico baixo, nenhuma possuía esse tipo de equipamento.

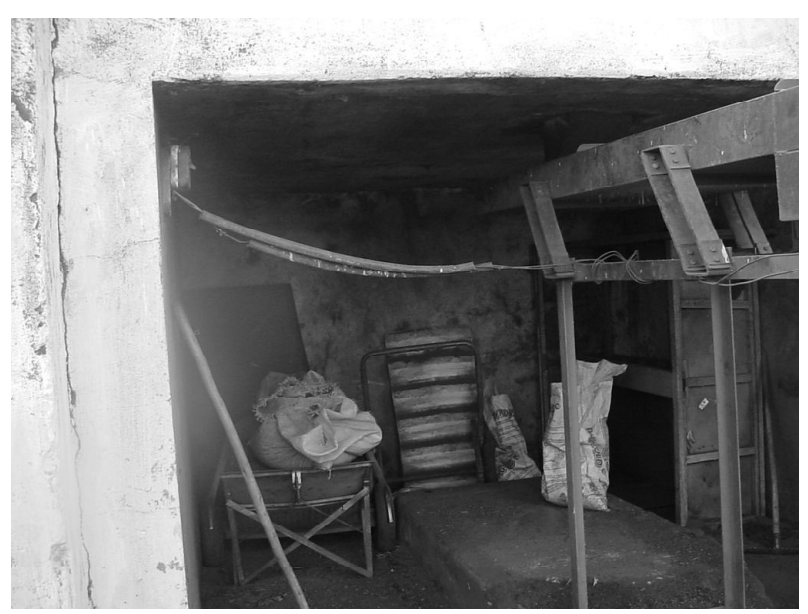

Figura 2 - Fiação exposta e sem proteção.

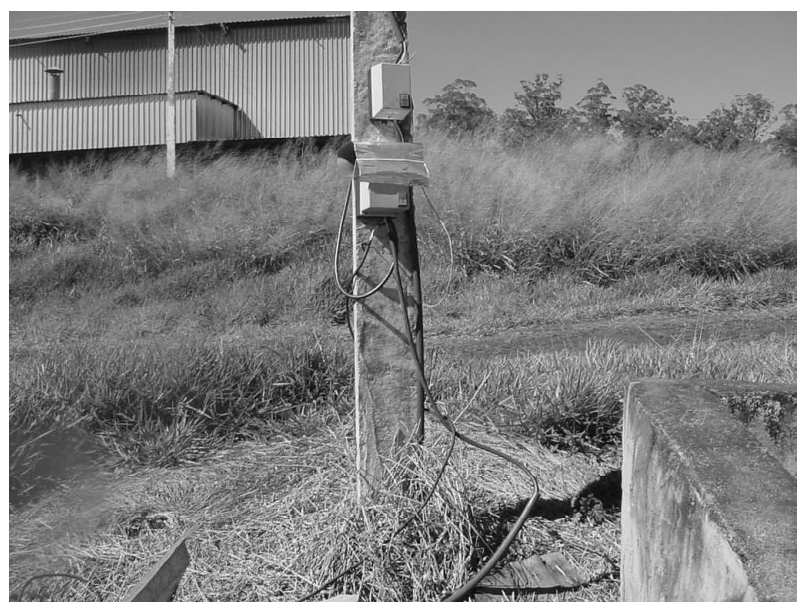

Figura 3 - Painel de comando sem proteção.

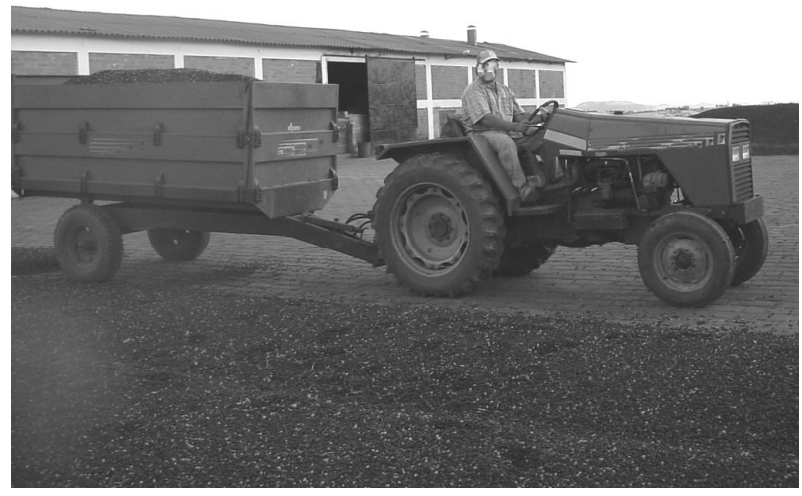

Figura 4 -Trator sem cabine de proteção e trabalhador sem EPIs. 


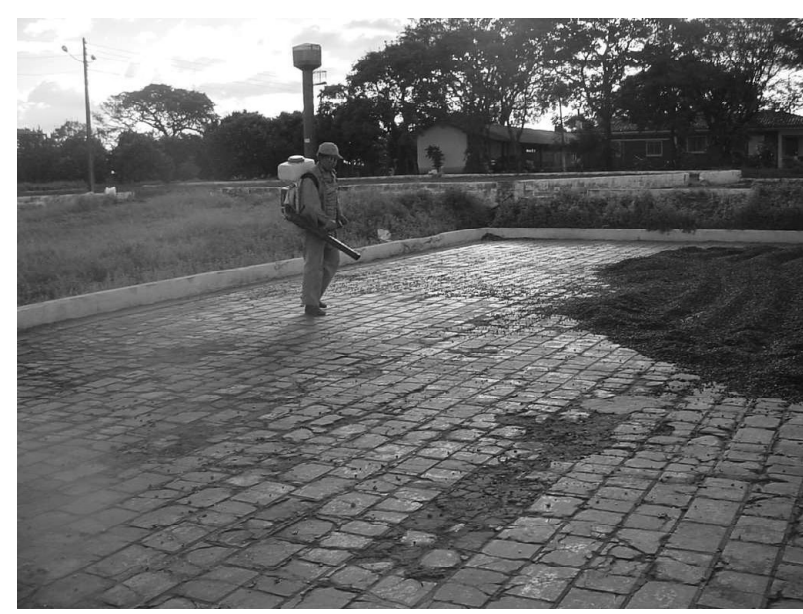

Figura 5 - Trabalhador empurrando café com bomba costal.

O principal risco existente para o trabalhador em locais onde se encontram os secadores é o risco de explosão e incêndios, principalmente quando se trata de secadores e do pó que fica em suspensão.

Para reduzir os riscos de incêndios, algumas medidas devem ser adotadas seguindo as conformidades da NR 20 da Portaria nº3.214 de 8 de junho de 1978. Nos locais onde são armazenados combustíveis e na sua área de segurança, deverão conter placas com dizeres "Proibido fumar e Explosivos", que possam ser observadas por todos que tenham acesso ao local. Segundo a NR 20, o local deve ter proteção contra intempéries, protegida com páraraios, dotados de sistema eficiente e adequado para o combate a incêndio, devido ao armazenamento de líquidos combustíveis e inflamáveis. Os combustíveis devem estar a uma distância de no mínimo 50 metros do armazém, residências e postes de eletricidade (alíneas d, f, g, h, i, j, 1 e m da NR 16 da Portaria n³.214 de 8 de junho de 1978). Os funcionários que ficarem responsáveis pelo manuseio do combustível devem passar por treinamento. Além disso, manter o local limpo evita explosões e incêndios. Nas Figuras 6 e 7, é possível observar os registros feitos nos locais que ofereciam riscos de explosão. Destaca-se nessas Figuras 6 e 7, a quantidade de pó que sai dos secadores e fica suspenso no ar. Esse pó, em conjunto com uma fonte de ignição e $\mathrm{O}_{2}$ do ambiente, pode ocasionar incêndio e até mesmo explosão. Além de ser totalmente prejudicial à saúde do trabalhador, pois ele causa irritação nos olhos e pode ser inspirado pela pessoa que trabalha no local, causando doenças pulmonares e respiratórias por ser acumulativo no pulmão. Outro risco ao trabalhador existente nos secadores é o ruído que é muito alto, incômodo, dificulta a comunicação e causa problemas auditivos.

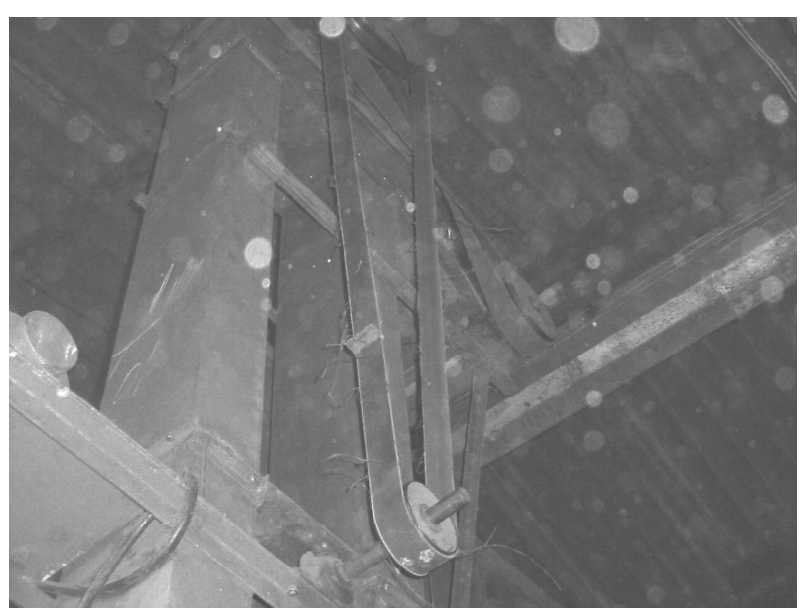

Figura 6 - Polia exposta e local cheio de pó.

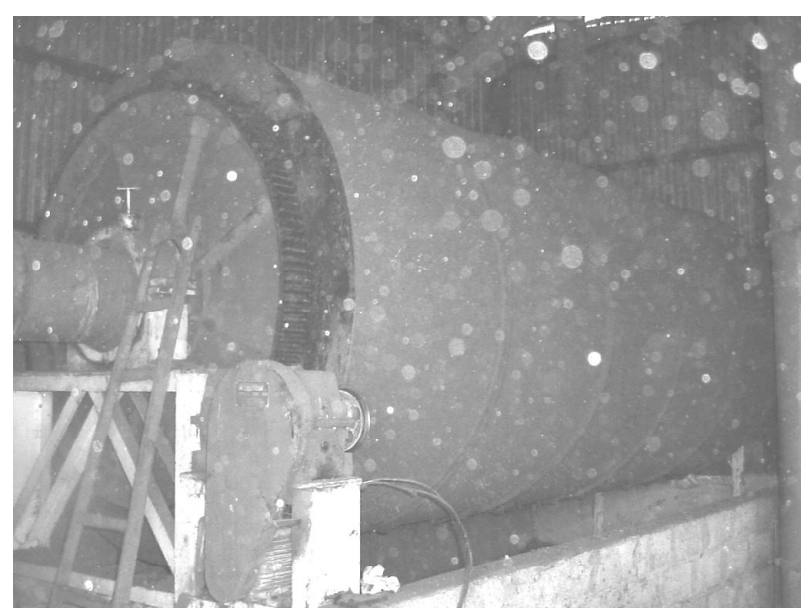

Figura 7 - Secador rotativo a gás com muito pó no ambiente.

No trabalho de alimentação da fornalha de secadores à lenha, o trabalhador está exposto à radiação e ao risco de queimaduras em consequiência do contato com o fogo. Na Figura 8(a) e (b), o funcionário trabalha muito próximo da abertura da fornalha, sem utilizar óculos para proteger os olhos e máscara para evitar a inspiração de fuligem. Além de não existir nenhum extintor de incêndio no local.

Nos depósitos onde os secadores ficam instalados, um equipamento que pode oferecer riscos é o painel de comando. Caso não esteja em bom estado de conservação, pode entrar em curto circuito e liberar faíscas, que servirão de fonte de ignição para desencadear um incêndio. Na Figura 9, pode ser observado,em destaque, um painel de controle que pegou fogo. Foram trocados alguns fios elétricos, mas ele continua sendo utilizado. 


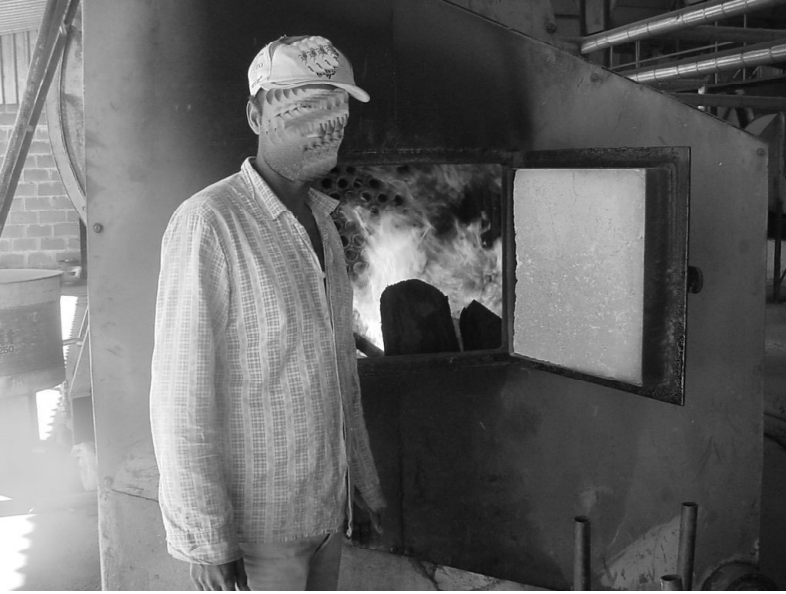

(a)

Figura 8 (a) e (b) - Trabalhador alimentando a fornalha.

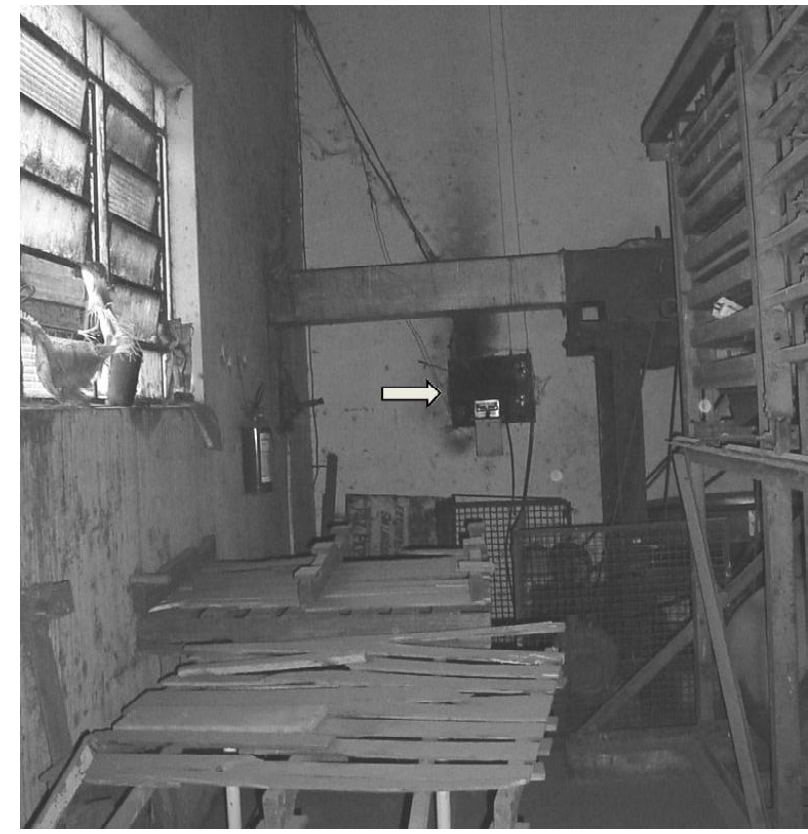

Figura 9 - Painel de comando após incêndio.

No caso de plataformas que são utilizadas para se fazer manutenção de secadores ou que serve de caminho até as tulhas, é necessária a instalação de corrimão e caso as plataformas possuírem mais de $2,00 \mathrm{~m}$ de altura, é necessário que tenha guarda-corpo e cinto de segurança. $\mathrm{O}$ dimensionamento das plataformas deve ser realizado por profissionais, de modo que sua estrutura de sustentação e fixação sejam de confiança e capazes de

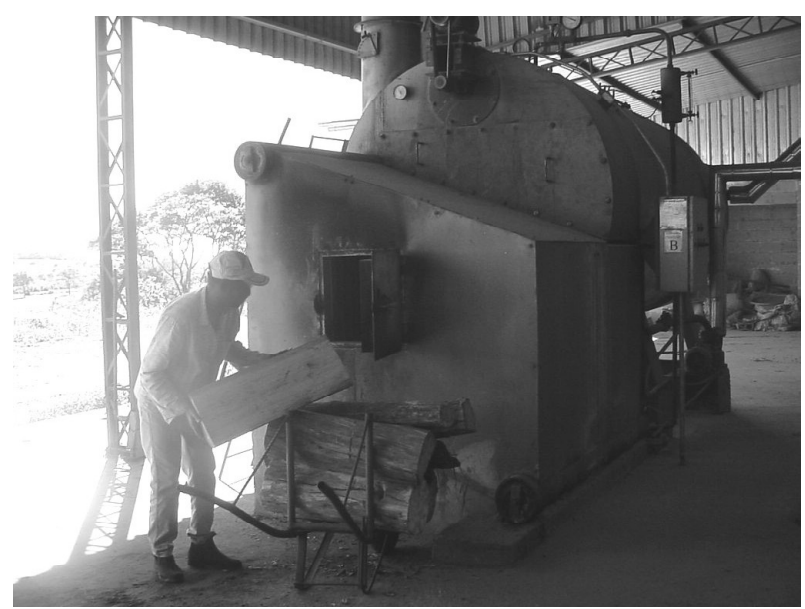

(b)

suportar o peso de pessoas e cargas (NR 18 da Portaria $\mathrm{n}^{\circ} 3.214$ de 8 de junho de 1978). Somente $3 \%$ das propriedades possuía a plataforma em excelente estado de conservação com corrimão. A Figura 10 ilustra uma escada que possui mais de 2,00 metros de altura e não possui guarda-corpo e cinto de segurança.

Os acidentes ocorridos em função da falta de proteção nos equipamentos e máquinas são um grande problema nas propriedades, pois a maioria não possui envoltório nas polias e correias, gerando riscos de acidentes como perda de membros. Esse risco pode ser observado nas Figuras 11 e 12, em todas as polias e as engrenagens estão totalmente expostas. Segundo o item 12.3 da NR 12, as máquinas e equipamentos devem ter suas transmissões de força enclausuradas dentro de sua estrutura, ou devidamente isoladas por anteparos adequados, mas que possam ser removidos no caso de limpeza ou manutenção, sendo que a recolocação seja imediata.

Os riscos ocultos são de difícil percepção e totalmente desconhecidos pela maioria dos trabalhadores, geralmente ficam escondidos ou ninguém percebe que eles podem causar algum acidente. É o caso, por exemplo, de madeira dependurada no telhado servindo de plataforma e que pode ser observada na Figura 13, que apresenta um andaime improvisado com sacaria de juta. Em consequiência do péssimo estado de conservação e à forma como está preso ao teto, pode cair e oferecer riscos aos trabalhadores. 
Os riscos observados durante o armazenamento de café, são basicamente os mesmos encontrados no processo de secagem, como o ruído feito pelas máquinas empilhadoras, painel de controle irregular, instalações elétricas inadequadas, além das escadas e plataformas de acesso às tulhas, estarem em desacordo com as normas regulamentadoras rurais.

Durante a visita realizada nas propriedades, encontrou-se somente uma esteira utilizada para empilhar as sacarias de café (facilita a atividade do funcionário) que são armazenados na propriedade ou que aguardam até o momento de serem transportadas para cooperativas ou que são diretamente comercializadas. Um equipamento utilizado para empilhar as sacarias de café e que pode oferecer riscos a segurança do trabalhador é o guindaste. Este equipamento funciona também como risco oculto, porque fica localizado em locais que podem gerar algum acidente, além de ter ganchos expostos. A Figura 14 mostra um modelo de guindaste utilizado nas propriedades.

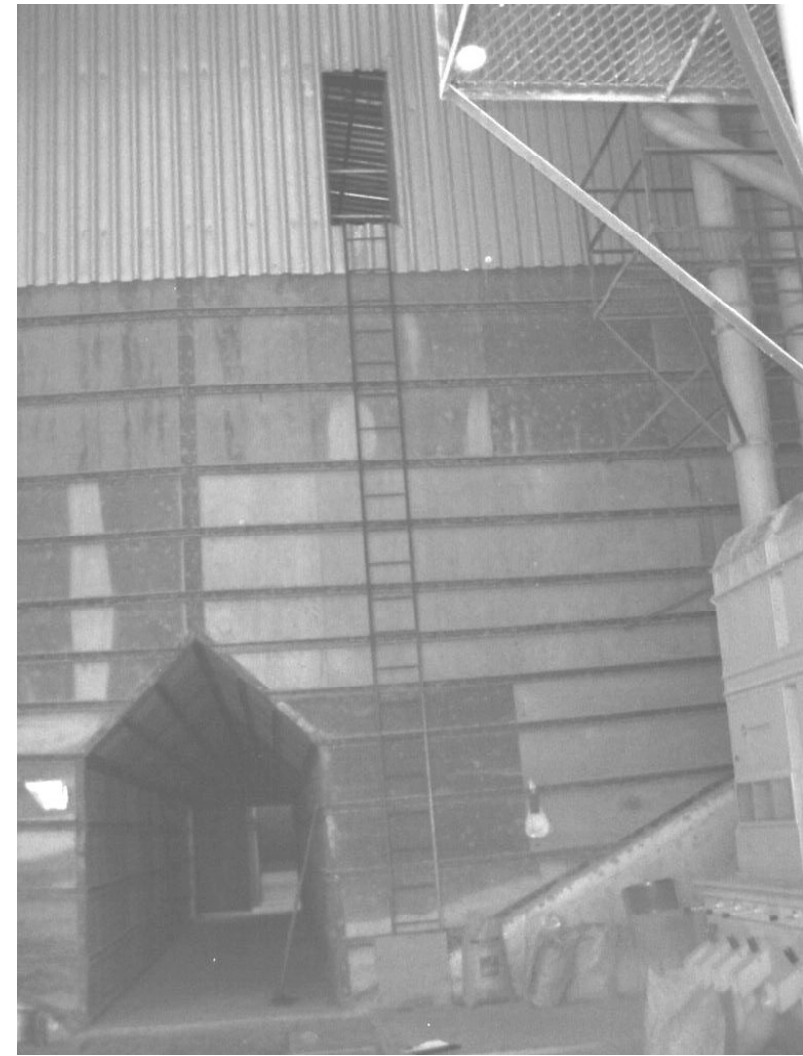

Figura 10 - Escada com mais de 2,00 metros de altura.

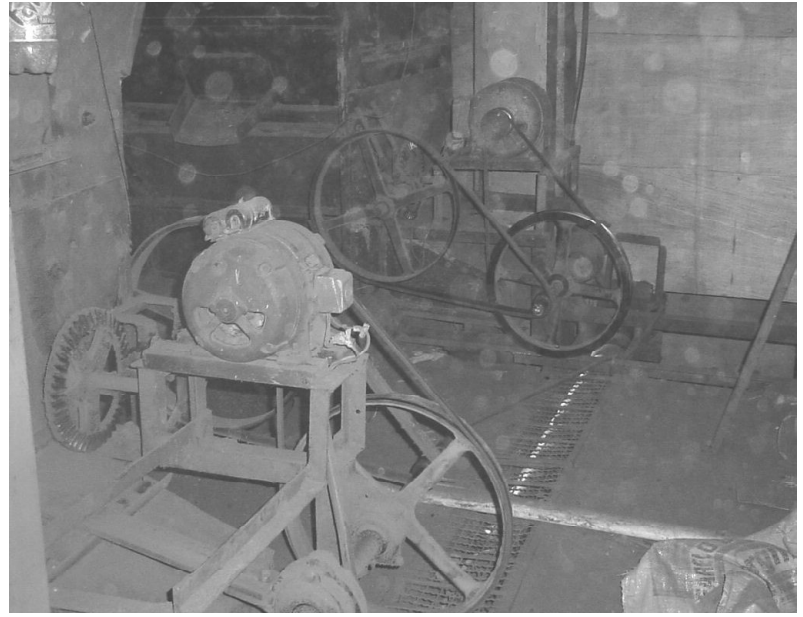

Figura 11 - Polias e engrenagens sem proteção.

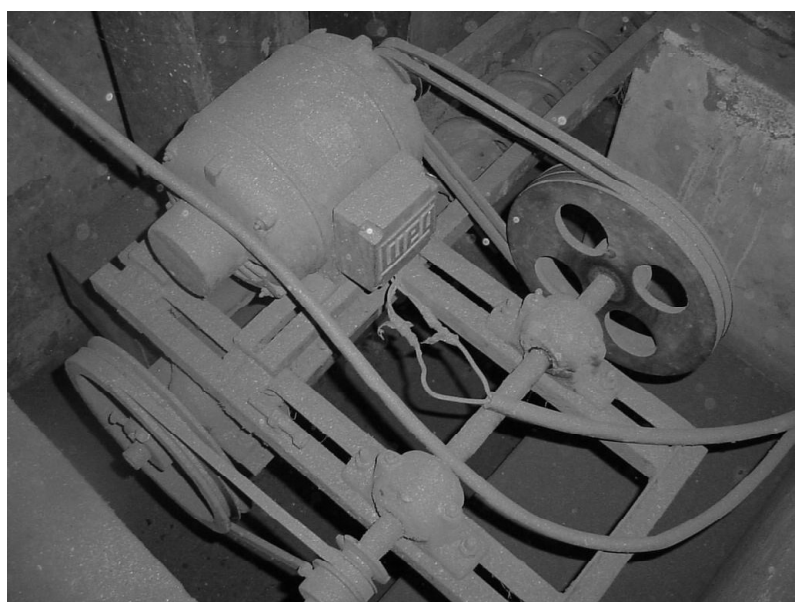

Figura 12 - Polias e fios elétricos sem proteção.

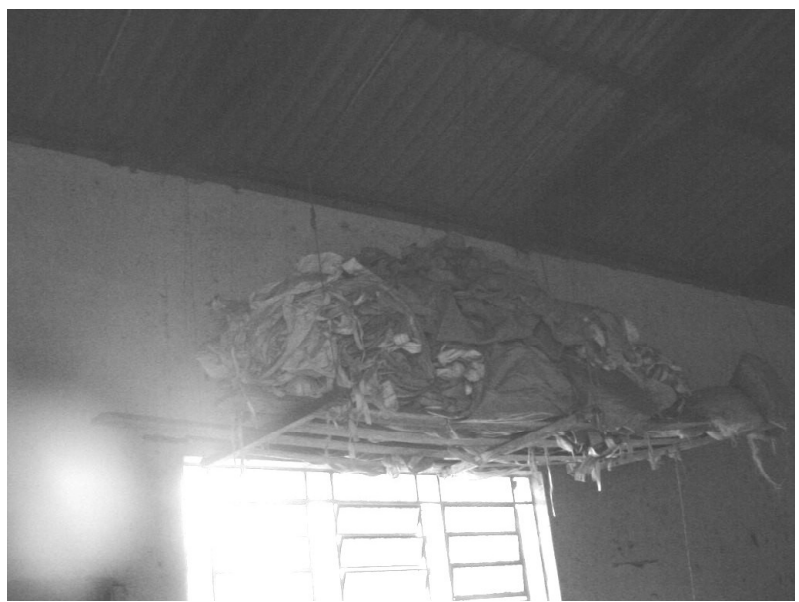

Figura 13 - Sacarias sobre andaime 


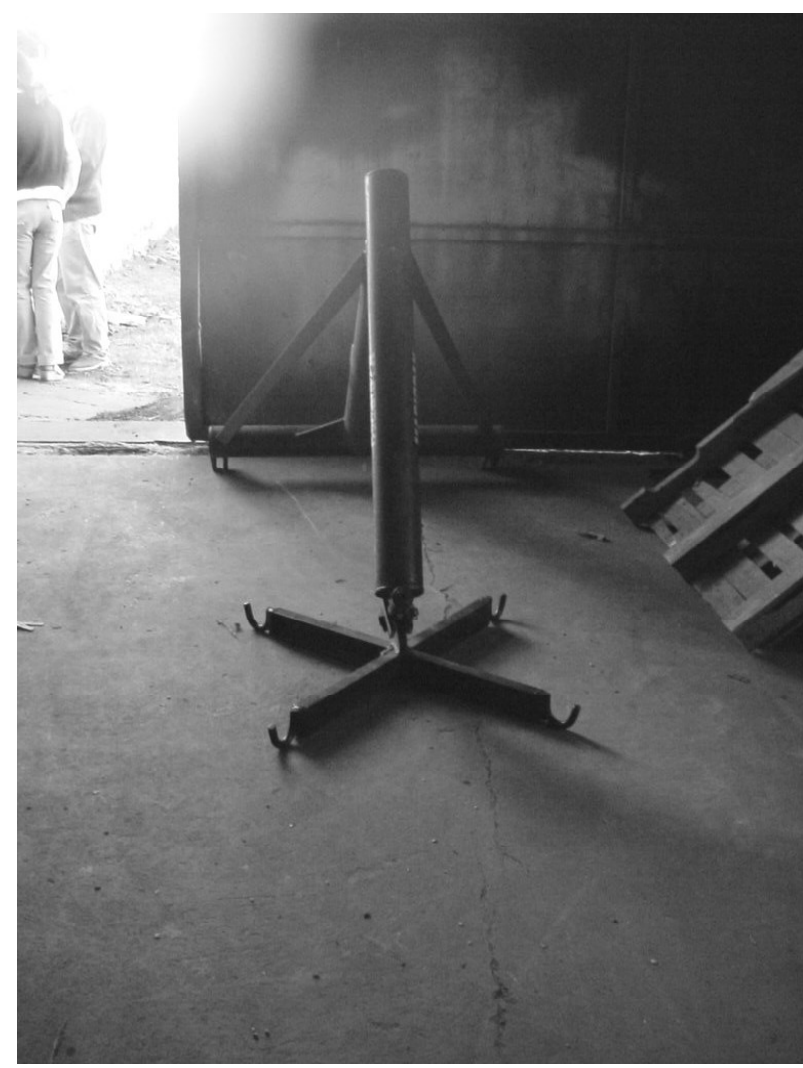

Figura 14 - Guindaste para erguer sacarias em local de trânsito de pessoas.

O processo de beneficiamento pode ser realizado tanto na propriedade como em caminhões que circulam pelas propriedades fazendo o descascamento do café. As propriedades classificadas em baixo nível tecnológico não apresentavam estrutura para o beneficiamento do café, predominando, nas associações de pequenos produtores, o beneficiamento realizado por um conjunto móvel. Somente $30 \%$, beneficiam o café na própria fazenda. Os riscos existentes à segurança e à saúde do trabalhador são equivalentes aos riscos do secador, portanto as normas regulamentadoras aplicáveis para o bom funcionamento da máquina beneficiadora equivale às NR's do lavador e do secador. Um exemplo de má conservação da máquina de beneficiamento é a Figura 15 , as junções estão quase todas amarradas com pano e borracha e as polias expostas. Essa falta de proteção expõe o trabalhador a vários riscos, como incêndio, queda de alguma parte da estrutura, dentre outros já discutidos. A Figura 16 destaca a falta de proteção ao redor das polias e a sujeira do local.

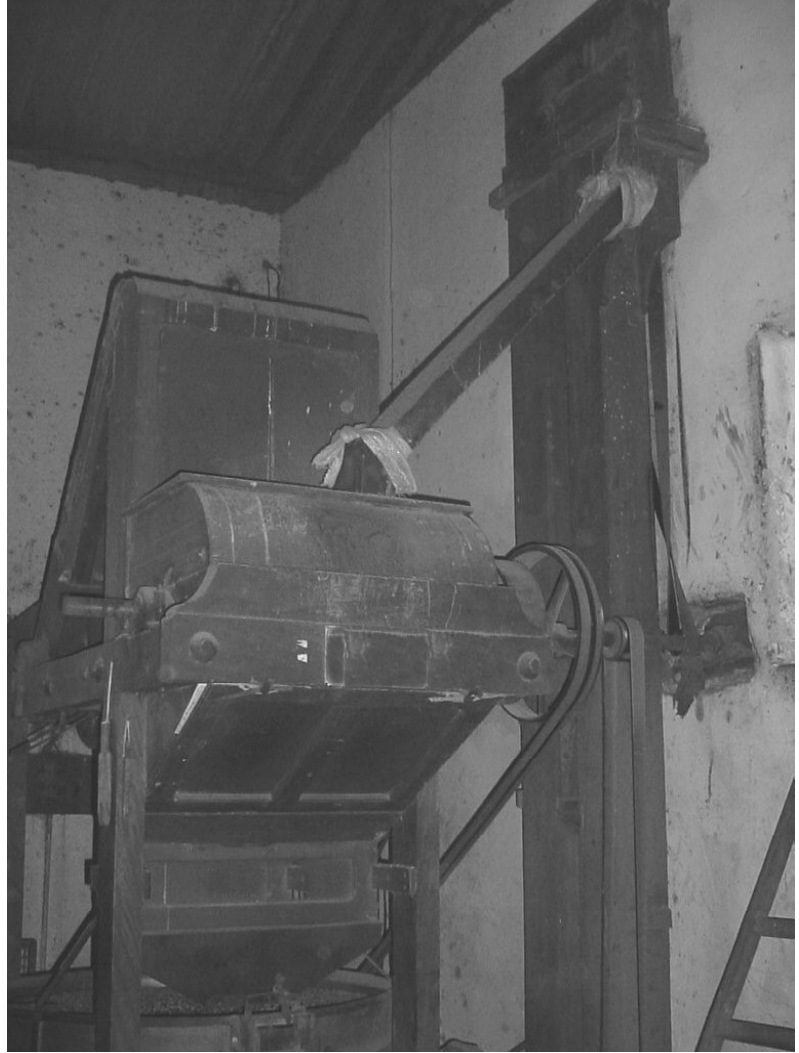

Figura 15 - Máquina de beneficiamento.

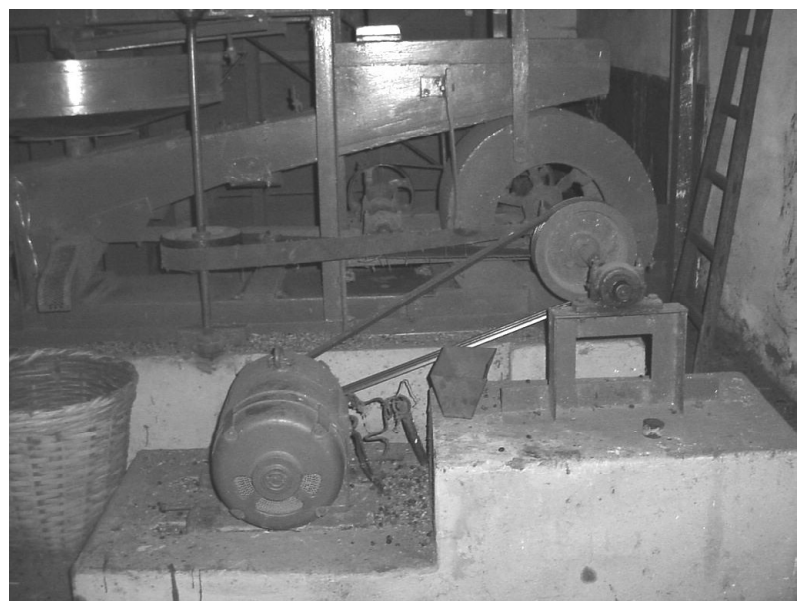

Figura 16 - Polias sem proteção e local sujo.

Desta forma, pôde-se observar que todas as etapas do processamento possuem máquinas e equipamentos que oferecem riscos à segurança e à saúde do trabalhador. 
Quanto maior o poder aquisitivo dos produtores, maior a percepção dos riscos existentes na atividade e, conseqüentemente, maior é a preocupação em adaptar as atividades segundo as normas do Ministério do Trabalho e do Emprego.

Somente 3\% das propriedades estavam totalmente de acordo com as Normas Regulamentadoras, e outros 3\% estavam em processo de modificação na fazenda para implantação das normas. Em oitenta e quatro por cento das propriedades as instalações estavam totalmente em desacordo com as conformidades das normas regulamentadoras.

\section{REFERÊNCIAS BIBLIOGRÁFICAS}

BINDER, M. C. P.; WLUDARSKI, S. L.; ALMEIDA, I. M. de. Estudo da evolução dos acidentes do trabalho registrados pela Previdência Social no período de 1995 e 1999, em Botucatu - SP. Caderno de Saúde Pública, Rio de Janeiro, v. 17, n. 4, p. 915-924, jul./ago. 2001.

BRASIL. Ministério do Trabalho. Portaria 3214, de 8 de junho de 1978. Lei n. 6.514, de 22 de dezembro de 1977. São Paulo: Atlas, 2004.

GLOBAL EXCHANGE. Fair trade. 2004. Disponível em $<\mathrm{http} /$ 'Lwww.globalexchange.org/campaigns/fairtraded coffee $>$. Acesso em: 10 jan. 2005.
JANSSON, B. R.; JACOBSSON, D. S. Medical consequences of work-related accidents on 2454 Swedish farms. Scandinavian Journal of Work, Environment and Health, Helsinki, v. 1, n. 14, p. 21-26, Feb. 1988.

LACERDA, G. Mercado internacional é promissor. 1998. Disponível em: <http/T్www.agr.féis.unesp.br/café.htm. Acesso em: 10 jan. 2005.

LUPI, K. Fatal occupational accidents in agriculture in 1984. Lyoterreyslaitoksen Lutkimuksia, [S.1.], v. 3, p. 343-351, 1985.

MEKAY, E. Café: apoio do banco mundial ao comércio justo: ambiente global. 2005. Disponível em: <http// www2.uol.com.br./ambienteglobal/site/reportagens>. Acesso em: 10 jan. 2005.

OLIVEIRA, J. S.; PORCARO, R. M.; JORGE, A. F. Mudanças no perfil de trabalho e rendimento no Brasil. In: Indicadores sociais: uma análise da década de 1980. Rio de Janeiro: FIBGE, 1995. p. 145-176.

PERES, F.; LUCCA, S. R. de; PONTE, L. M. D. da; RODRIGUES, K. M.; ROZEMBERG, B. Percepção das condições de trabalho em uma tradicional comunidade agrícola em boa Esperança, Nova Friburgo, Rio de Janeiro, Brasil. Caderno de Saúde Pública. Rio de Janeiro, v. 20, n. 4, jul./ago. 2004. 